\title{
25 Research Soure \\ Selection of Feasible Leaching Method for Recovery of Heavy Metals from E-waste using Analytic Hierarchy Approach
}

\section{Garima Minocha}

Guru Gobind Singh Indraprastha University

vinita khandegar ( $\square$ vinita@ipu.ac.in )

Guru Gobind Singh Indraprastha University

\section{Sanigdha Acharya}

Guru Gobind Singh Indraprastha University

\section{Research Article}

Keywords: Leaching methods, AHP technique, E-waste, Recovery, Heavy metals

Posted Date: September 24th, 2021

DOI: https://doi.org/10.21203/rs.3.rs-769895/v1

License: (c) (i) This work is licensed under a Creative Commons Attribution 4.0 International License.

Read Full License 


\section{Abstract}

Amount of e-waste is increasing tremendously over the years, from almost getting doubled each year. 40 $\%$ e-waste consists of many metals and precious metals. The rapid growth in technology development is alarming, as a result more and more e-waste is generating. This leads to myriad problems for handling or management of e-waste. Traditional methods of disposal of e-waste such as landfilling, composting and incineration is major threat to the environment and life. In this study recovery of metals through hydrometallurgical process such as thiosulfate (M1), iodide (M2) aqua-regia (M3) and thiourea (M4) leaching methods were compared in terms of economic feasibility, environmental impact and reagent reuse in order to find out a feasible leaching method using Analytic Hierarchy Process (AHP). The selection of feasible leaching method has been performed by applying the Saaty, ranking. From the final ranking are, thiosulfate $(M 1)$ scored $=0.09$, iodide $(M 2)=0.16$, aqua-regia $(M 3)=0.39$ and thiourea $(M 4)=0.39$. From the result M3 and M4 are the feasible method for recovery of heavy metals from E-waste.

\section{Introduction}

E-waste is referred to the electrical and electronic equipment which have reached end of their useful life. In last 10 years utilization of hardware and electrical gear are increasing very drastically and simultaneously e-waste are also generating harshly. E-waste contains over $60 \%$ precious and nonmetals parts and many are valuable, some are hazardous, and some are both. High rate of e-waste generation could be a threat to the environmental pollution due to its hazardous components. Therefore, e-waste generating and management is a new emerging problem in the globe (Chatterjee 2011). Some definitions from literature are:

European WEEE Directive "Electrical or electronic equipment which is waste ... including all components, sub-assemblies and consumables, which are part of the product at the time of discarding." (European 2014).

Basel Action Network "E-waste encompasses a broad and growing range of electronic devices ranging from large household devices such as refrigerators, air conditioners, cell phones, personal stereos, and consumers electronics to computers which have been discarded by their users." (Puckett et al. 2002).

E-waste contains a number of constituents which can be divided into 5 categories- ferrous metals, nonferrous metals, glass, plastics and others. The first major constituent is metals and plastic are the second by weight. As per Association of plastics manufacturing, the electronic and electrical products contain ferrous $38 \%$, nonferrous $28 \%$, glass $4 \%$, plastics $19 \%$, others $10 \%$, and wood $1 \%$, (See Fig. 1) (European 2014).

Electronic and Electrical products are converting in E-waste due to hasty progresses in technologies and more frequent replacement of these products by consumers (Chatterjee 2011). E-waste is produced by mainly from institutions, household, and manufacturing sectors, etc. Disposal of e-waste is a major global and environmental concern. This waste has become the most tremendously growing segment of 
the municipal waste in world. The major problem lies as to how to carry out safe and efficient disposal of E waste. This type of waste has been exponentially growing over the last many decades and accumulation may lead to biohazards. However, in up-to-date products contains up to 57 different elements. As per Kaya (2016), The most complex structure in electronic and electrical item is present in printed circuit boards. Different categories of E-waste are presented in Fig. 2.

Waste electronic items contains numerous components that are hazardous and toxic in nature. Therefore, they should be recycled by scientifically sustainable techniques, otherwise it may lead to devastating impact on life, environment and climate. If recycling is done properly, then waste electronic items provide immense value addition and drives great economic aspect (Frazzoli et al. 2010). One of the most used methods for E-waste disposal is landfilling, which poses several problems. The landfill sites release hazardous emissions. Mercury, cadmium and lead are the most toxic elements in the leachate (Frazzoli et al. 2010; Vidyadhar 2016).

As the amount of e-waste is increasing exponentially over the years and the practices of recycling them and disposing them off in landfills is a matter of environmental concern, it is necessary to find out a proper method for the extraction of metals from the E-waste as this will ace the recycling process. The process selected should be such that it is environmentally sound and economically viable. Therefore, the aim of this study is to find out the feasible leaching method for recovery of heavy metals from E-waste using Analytic hierarchical process based on the criteria of economic feasibility, environmental impact and reagent reuse.

\section{Literature Survey}

\section{Status of India in Global scenario}

The main reasons for the significant increment in e-waste generation are development of new technologies, human mentality, and very important is population. As per the report given in 2018 by Associated chambers of commerce and industry of India, 2 MT per annual e-waste is formed in India in 2018 and comes in top five countries in the world, after China, USA, Japan and Germany (Awasthi et al. 2016; Ahuja and Bhaskar 2018). But according to published article in Times of India in 2020 by Mohan (2020), India generating 3.2 MT per annual and third largest e-waste generating country in the world after China and USA which are generating e-waste 10.1 and 6.9 MT per annual respectively. As per Mohan (2020) About $38 \%$ of global e-waste is generated by these three countries. On per capita scales, Europe ranks first ( $16.2 \mathrm{Kg} /$ capita) and Oceania ranks second (13.3 Kg/capita) followed by America (13.3 $\mathrm{Kg} /$ capita) while India per-capita e-waste generation is much lower (2.4 kg/capita).

\section{Indian scenario}

In India major sixty five cities are generating $>60 \%$ of the total e-waste, while, 10 states are generated $70 \%$ of the total e-waste (Chatterjee 2011). Maharashtra, Gujarat, Tamil Nadu, Uttar Pradesh, West Bengal, Andhra Pradesh, Karnataka, Madhya Pradesh, and Delhi are the major states in which e-waste generation 
is very high. In comparison with the city wise e-waste generation, Mumbai is the top first city which generated $24 \%$ e-waste. Fig. 3 shows state wise e-waste generation in India.

The main factors for growth of e-waste in India are discussed below:

- Consumer End: Discarding of e-waste is a large issue from consumer point of view. Basically, some e-wastes like computer peripherals are reused/ recycled more in India compared to developed countries with resale and repair facilities. Still few e-wastes become obsolete when consumer loses interest.

- Market factors: large software industries use cutting edge technologies, greater computing speed and improved efficiency, thus, it increases the rate of obsolescence. Further, with growth in standard of living, banks are providing affordable loans and dealers provide easy instalment facilities (Pandey and Govind 2020).

City wise generation of e-waste is shown in Fig. 4. It can be seen from Fig. 4 that, amongst top 10 cities, Mumbai ranks $1^{\text {st }}$ in generating e-waste. IT sector plays a big role for the growth of economy of India on one hand, whereas on the other it has led to the increase in the consumption of electronic components and a tremendous growth of e-waste in the country. It is necessary to develop comprehensive and robust mechanism for waste disposal before it becomes unmanageable (Turaga et al. 2019).

Fig. 4 City wise E-waste generation in India

\section{Recovery of Heavy metals}

Waste electrical and electronics equipment's processing is very complex due to its heterogeneous composition (Birloaga and Vegliò 2018). Therefore, various extraction process is used in order to separate or recover the heavy metals. Various metal extraction process is shown in Fig. 5. Generally, two key steps such as pre-processing and end-processing involved in recovery of heavy metals. In preprocessing, the equipment's that have expired are dismantled manually at collection sites (Khaliq et al. 2014). Then the components are tested and secluded from WEEE. Initially, housing cabinet, all wirings, and drive boards are separated. After that mechanical processing is applied using hammer mills for cutting the E-waste in small pieces. Then metals, non-metals, plastic are separated using different separation techniques such as screening, magnetic, eddy current and density. Final stage in endprocessing in which metal extraction takes place by chemical processes via pyrometallurgy, hydrometallurgy, electrometallurgy or bio-metallurgy techniques.

The metal portions separated from electronic waste through end-processing and their combinations. The pyro-metallurgical and hydro-metallurgical methods are the major paths for processing of electronic waste. Apart from these routes/methods, there are other methods like electrochemical or electrometallurgical processes (for example, we have electrowinning or electrorefining) for certain metal separation and recovery. Every method has its advantages and disadvantages that must be taken into consideration for the selection of a fitting recycling process of metal recovery. 


\section{Hydro-metallurgy process}

Hydrometallurgical process comprise of a sequence of acid or caustic leaching of E-waste (Cui and Roven 2011). We cannot completely extract precious metals by directly using pyro-metallurgical processing. Therefore, the residues of copper and nickel from smelters are send for further processing. In hydro-metallurgy process, heavy metals are separated from acid and caustic solutions through precipitation, solvent extraction, adsorption and ion-exchange process (Havlík 2008; Tunsu and Retegan 2016). Leaching method involves the reaction of solid components when exposed to leaching agent. In these method precious metals targeted using chemicals and titration techniques from the solution of metal complex. Leaching agents such as thiosulfate, alkali, cyanide, and many acids are used. In acids, hydrochloric acid $(\mathrm{HCl})$, sulfuric acid $\left(\mathrm{H}_{2} \mathrm{SO}_{4}\right)$ and nitric acid $\left(\mathrm{HNO}_{3}\right)$ are used. After using of leaching agents, target element is settled by a gravity into the liner and sent for additional processing or recovery of the metals Chauhan (2018). Leaching parameters are influenced by particle sizes, dose of solvents used, temperature, and the leaching time. The major challenge during the extraction of precious metals is formation of metal complexes with other metals. Though, chemical leaching is more preferable as compare to pyro-metallurgical processes. Further these process does not release harmful gases and particulate matters in the environment. These process consumes very less energy (Ashiq et al. 2019). Also, the recovery rates are higher and easy operation as compare to other process (Dissanayake 2014). The advantages of hydro-metallurgical methods include, better control, more precision, and greener option as compared to the high operating temperatures of pyrometallurgy process. However, the main disadvantages of hydrometallurgical methods are time consuming, slow, and impact the recycling economy. During termination and subsequent steps there is risk of precious metal loss, hence total recovery of metals is affected (Chauhan et al. 2018).

\section{Methodology}

\section{Analytic hierarchy process}

Analytical hierarchy process is a decision making tool developed by Thomas L. Saaty of the University of Pittsburg (Saaty 1977). AHP is used when has various measures are available for comparison (Yu 2017).

\section{Development of a hierarchy model}

In this step, a three-level hierarchy model was developed as shown in Fig. 6 to select the suitable leaching method using AHP. Criteria and sub-criteria are discussed in detail.

Fig. 6 Three-level hierarchy model for selection of feasible leaching method

\section{Selection of criteria}

Several leaching methods used for the recovery of metals from e-waste. The main criteria that will assist in deciding the suitable process for heavy metal recovery are represented here, i.e., economic feasibility, 
environmental impact, and reagent reuse.

\section{Economic feasibility (EF)}

Economic feasibility is the economic analysis of the process, which include all expenditure or investment during the process. If all the expenditure are in low cost, then the process is called as an economically feasible process.

\section{Environmental impact (El)}

Environmental impact refers to the impact on the ecosystem. A suitable method should not impact or harm the environment.

\section{Reagent reuse (RR)}

In leaching process reagent is the heart of the process, therefore, it should be reused again and again. Regeneration of reagent is a good characteristic of economic and eco-friendly process.

\section{Selection of sub-criteria}

On the basis of criteria, six sub-criteria such as leaching rate, reagent cost, toxicity, safety, corrosiveness, and reagent regeneration were selected for all the four methods.

\section{Leaching Rate (LR)}

Leaching rate is related to the kinetics of a process i.e., how much heavy metal is recovered in a particular time. A suitable method should have high leaching rate.

\section{Reagent Cost (RC)}

Reagent cost is the cost of reagent used for recovery of $1 \mathrm{~g}$ of e-waste. A suitable method should have low reagent cost.

\section{Toxicity (TO)}

Toxicity is the degree at which the reagent can harm the environment (organism) and human beings. A suitable method should be less toxic to flora and fauna.

\section{Safety (SF)}

Safety includes the condition of being protected from unlikely caused danger, risk, or injury. A suitable method should be safe.

\section{Corrosiveness (CO)}


Corrosiveness means the ability of a reagent to cause corrosion. A suitable method should be non-toxic and non-corrosive in nature.

\section{Regeneration (RG)}

After the completion of one cycle of recovery, the reagent can be recovered and used again for subsequent cycles. If regenerated reagent recovers in good amount, then the process is considered as suitable method.

\section{Alternative}

Comparison was made between thiosulfate (M1), iodide (M2) aqua-regia (M3) and thiourea (M4) for recovery of heavy metals.

\section{Pairwise comparison matrix}

In AHP, pairwise comparisons are made to get exact ratio scale priorities. A pairwise comparison matrix is constructed for each level (criteria, sub-criteria and alternatives) and generate a matrix of relative rankings. For example, comparing LR to all six sub-criteria, i.e., LR, RC, TO, SF, CO, and RG.

\section{Judgment for pairwise comparison}

In this step, judgments are made on the basis of decision makers experience and knowledge (literature survey). Pairwise comparison has been done as per Table 1. After that all values were normalized in the matrix by summing each column and then dividing each element of the matrix by the sum of its respective column to obtain the normalized pair-wise matrix which is called as priority vector (PV).

\section{Table 1 Scale for pair-wise comparisons Saaty (1977)}

\begin{tabular}{|lll|}
\hline Value & Definition & Explanation \\
\hline 1 & Identical value & Two requirements are of equal value \\
\hline 3 & Slightly more value & Experience slightly favours one requirement over another \\
\hline 5 & Strong value & Experience strongly favours one requirement over another \\
\hline 7 & Very strong value & Experience very strongly favours one requirement over another \\
\hline $2,4,6,8$ & Extreme value & Experience Extreme value favours one requirement over another \\
\hline Reciprocals & & When compromise is needed \\
\hline
\end{tabular}


i. For consistency verification, we multiply the value of criteria weights by each column of the pair-wise comparison matrix. Then we have to calculate the value of the weighted sum by summing the elements in each row and named as New Vector (NV).

ii. Maximum eigen value $\left(\lambda_{\max }\right)$ was calculated by averaging the value of NV/PV.

iii. Consistency index (Cl) was calculated using equation (1);

$C I=\left(\lambda_{\max }-n\right) /(n-1)$

where $\mathrm{n}$ is the number of elements.

iv. Consistency ratio (CR) was calculated using equation (2);

$\mathrm{CR}=\mathrm{Cl} / \mathrm{RI}$

where $\mathrm{RI}=$ Random Index (see Table 2 ). The value of $\mathrm{CR}<0.10$, only then the matrix is reasonably correct to make the decisions based on the AHP.

v. Finally, the criteria weights are used to decide the priority of each criterion and tells its percentage weightage when multiplied by 100 .

Table 2 Random index value

\begin{tabular}{|lllllllllll|}
\hline $\mathbf{n}$ & 1 & 2 & 3 & 4 & 5 & 6 & 7 & 8 & 9 & 10 \\
$\mathbf{R I}$ & 0.00 & 0.00 & 0.58 & 0.90 & 1.12 & 1.24 & 1.32 & 1.41 & 1.45 & 1.49 \\
\hline
\end{tabular}

\section{Results And Discussion}

Comparison of leaching methods from literature

Comparison of leaching methods was performed by literature survey and summarized in Table 3 .

Table 3 Comparison of leaching methods from literature survey (Li et al. 2018)

\begin{tabular}{|lllllll|}
\hline Criteria & EF & & El & & RG & \\
\hline Sub-criteria & LR & RC & TO & SF & CO & RG \\
\hline M1 & Medium & Medium & Low & High & Least corrosive & Very low \\
\hline M2 & High & Medium & Very low & High & Least corrosive & Low \\
\hline M3 & Fairly high & Medium & Medium & Low & Highly corrosive & High \\
\hline M4 & Fairly high & Low & Low & Medium & Fairly corrosive & Medium \\
\hline
\end{tabular}




\section{Pairwise comparison and consitency test of criteria}

Pairwise companion of criteria such as economic feasibility, environmental impact and reagent reuse were performed using Table 3 and the results are shown in Table 4. During the comparison, the first priority was given to economic feasibility, second to environmental impact and third to reagent reuse. From Table 4, The priority vectors for criteria $(E F=0.65, E l=0.23$ and $R R=0.12)$ were obtained.

Table 4 Pairwise comparison and consistency test of Criteria

\begin{tabular}{|c|c|c|c|c|c|c|c|}
\hline & EF & $\mathrm{El}$ & RR & PV & NV & NV/PV & Consistency test \\
\hline $\mathrm{EF}$ & 1 & 3 & 5 & 0.65 & 1.94 & 3.007 & $\lambda_{\max }=3.003$ \\
\hline $\mathrm{El}$ & $(1 / 3)$ & 1 & 2 & 0.23 & 0.69 & 3.002 & $\mathrm{Cl}=0.0018$ \\
\hline $\mathrm{RR}$ & $(1 / 5)$ & $(1 / 2)$ & 1 & 0.12 & 0.36 & 3.001 & $C R=0.0013$ \\
\hline
\end{tabular}

\section{Pairwise comparison and consitency test of sub-criteria}

Pairwise companion of sub-criteria such as leaching rate, reagent cost, toxicity, safety, corrosiveness, and reagent regeneration were performed using Table 1 and Table 3. Results are shown in Table 5. During the comparison priority was set as per the literature. From the Table 5 , the priority vectors for sub-criteria are $\mathrm{LR}=0.33, \mathrm{RC}=0.67, \mathrm{TO}=0.17, \mathrm{SF}=0.83, \mathrm{CO}=0.2$, and $\mathrm{RG}=0.8$.

\section{Pairwise comparison and consitency test of leaching methods (Alternatives)}

Pairwise companion of leaching methods $M 1, M 2, M 3$ and $M 4$ with respect to sub-criteria leaching rate, reagent cost, toxicity, safety, corrosiveness, and reagent regeneration were performed using Table 1 and Table 3 and the results are shown in Table 6, Table 7 and Table 8.

Table 5 Pairwise comparison and consistency test of Sub-criteria 


\begin{tabular}{|c|c|c|c|c|c|c|}
\hline & LR & $\mathrm{RC}$ & PV & NV & NV/PV & Consistency test \\
\hline LR & 1 & $1 / 2$ & 0.33 & 0.67 & 2 & \multirow[b]{3}{*}{$\lambda_{\max }=2$} \\
\hline \multirow[t]{2}{*}{$\mathrm{RC}$} & 2 & 1 & 0.67 & 1.33 & 2 & \\
\hline & TO & $\mathrm{SF}$ & PV & NV & NV/PV & \\
\hline TO & 1 & $1 / 5$ & 0.17 & 0.33 & 2 & $\mathrm{Cl}=0$ \\
\hline \multirow[t]{3}{*}{ SF } & 5 & 1 & 0.83 & 1.67 & 2 & $\mathrm{RI}=0$ \\
\hline & & & & & & $\mathrm{CR}=0$ \\
\hline & $\mathrm{CO}$ & RG & PV & NV & NV/PV & \\
\hline $\mathrm{CO}$ & 1 & $1 / 4$ & 0.2 & 0.4 & 2 & \\
\hline RG & 4 & 1 & 0.8 & 1.6 & 2 & \\
\hline
\end{tabular}

Table 6 Pairwise comparison and consistency test of leaching methods 


\begin{tabular}{|c|c|c|c|c|c|c|c|c|}
\hline For LR & M1 & M2 & M3 & M4 & PV & NV & NV/PV & Consistency test \\
\hline M1 & 1 & $(1 / 3)$ & $(1 / 5)$ & $(1 / 5)$ & 0.07 & 0.29 & 4.36 & $\lambda_{\max }=4.16$ \\
\hline M2 & 3 & 1 & $(1 / 4)$ & $(1 / 4)$ & 0.13 & 0.56 & 4.29 & $\mathrm{Cl}=0.054$ \\
\hline M3 & 5 & 4 & 1 & 2 & 0.54 & 2.13 & 3.95 & $\mathrm{RI}=0.90$ \\
\hline M4 & 5 & 4 & $(1 / 2)$ & 1 & 0.37 & 1.49 & 4.06 & $C R=0.061$ \\
\hline For RC & M1 & M2 & M3 & M4 & PV & NV & NV/PV & Consistency test \\
\hline M1 & 1 & $(1 / 3)$ & $(1 / 3)$ & $(1 / 5)$ & 0.07 & 0.31 & 4.14 & $\lambda_{\max }=4.201$ \\
\hline M2 & 3 & 1 & $(1 / 3)$ & $(1 / 4)$ & 0.14 & 0.58 & 4.05 & $\mathrm{Cl}=0.086$ \\
\hline M3 & 3 & 3 & 1 & $(1 / 4)$ & 0.23 & 1.03 & 4.40 & $\mathrm{RI}=0.90$ \\
\hline M4 & 5 & 4 & 4 & 1 & 0.55 & 2.43 & 4.44 & $C R=0.095$ \\
\hline For TO & M1 & M2 & M3 & M4 & PV & NV & NV/PV & Consistency test \\
\hline M1 & 1 & $(4 / 5)$ & 4 & $(1 / 3)$ & 0.22 & 0.89 & 4.10 & $\lambda_{\max }=4.15$ \\
\hline M2 & $(5 / 4)$ & 1 & 5 & $(5 / 4)$ & 0.35 & 1.42 & 4.12 & $\mathrm{Cl}=0.051$ \\
\hline M3 & $(1 / 4)$ & $(1 / 5)$ & 1 & $(1 / 4)$ & 0.07 & 0.28 & 4.12 & $\mathrm{RI}=0.90$ \\
\hline M4 & 3 & $(4 / 5)$ & 4 & 1 & 0.37 & 1.57 & 4.28 & $C R=0.057$ \\
\hline For SF & M1 & M2 & M3 & M4 & PV & NV & NV/PV & Consistency test \\
\hline M1 & 1 & $(1 / 3)$ & $(1 / 4)$ & $(4 / 5)$ & 0.10 & 0.42 & 4.10 & $\lambda_{\max }=4.18$ \\
\hline M2 & 3 & 1 & $(1 / 4)$ & $(4 / 5)$ & 0.18 & 0.75 & 4.11 & $\mathrm{Cl}=0.061$ \\
\hline M3 & 4 & 4 & 1 & 5 & 0.57 & 2.43 & 4.25 & $\mathrm{Rl}=0.90$ \\
\hline M4 & $(5 / 4)$ & $(5 / 4)$ & $(1 / 5)$ & 1 & 0.14 & 0.61 & 4.28 & $C R=0.067$ \\
\hline For CO & M1 & M2 & M3 & M4 & PV & NV & NV/PV & Consistency test \\
\hline M1 & 1 & $(1 / 3)$ & 5 & 4 & 0.30 & 1.32 & 4.40 & $\lambda_{\max }=4.25$ \\
\hline M2 & 3 & 1 & 5 & 4 & 0.51 & 2.25 & 4.46 & $\mathrm{Cl}=0.085$ \\
\hline M3 & $(1 / 5)$ & $(1 / 5)$ & 1 & $(1 / 3)$ & 0.07 & 0.27 & 4.09 & $\mathrm{Rl}=0.90$ \\
\hline M4 & $(1 / 4)$ & $(1 / 4)$ & 3 & 1 & 0.13 & 0.53 & 4.08 & $C R=0.094$ \\
\hline For RG & M1 & M2 & M3 & M4 & PV & NV & NV/PV & Consistency test \\
\hline M1 & 1 & $(1 / 3)$ & $(1 / 7)$ & $(1 / 5)$ & 0.06 & 0.23 & 4.06 & $\lambda_{\max }=4.17$ \\
\hline M2 & 3 & 1 & $(1 / 6)$ & $(1 / 4)$ & 0.11 & 0.44 & 4.05 & $\mathrm{Cl}=0.059$ \\
\hline M3 & 7 & 6 & 1 & 3 & 0.56 & 2.42 & 4.31 & $\mathrm{RI}=0.90$ \\
\hline
\end{tabular}



M4
5
4
(1/3) 1
0.27
1.17
4.30
$\mathrm{CR}=0.065$

Table 7 Priority vectors for alternatives with respect to sub-criteria

\begin{tabular}{|lllllll|}
\hline PV values & LR (0.33) & RC (0.67) & TO (0.16) & SF (0.88) & CO (0.2) & RG (0.8) \\
\hline M1 & 0.06 & 0.07 & 0.22 & 0.1 & 0.3 & 0.05 \\
M2 & 0.13 & 0.14 & 0.35 & 0.18 & 0.51 & 0.10 \\
M3 & 0.54 & 0.23 & 0.07 & 0.57 & 0.07 & 0.56 \\
\hline M4 & 0.36 & 0.55 & 0.37 & 0.14 & 0.13 & 0.27 \\
\hline
\end{tabular}

Table 8 Overall priority vectors for alternatives with respect to sub-criteria

\begin{tabular}{|llll|}
\hline & PV for LR and RC & PV for TO and SF & PV for CO and RG \\
\hline M1 & $0.06 \times 0.33+0.67 \times 0.07=0.069$ & $0.22 \times 0.16+0.88 \times 0.1=0.123$ & $0.3 \times 0.2+0.8 \times 0.05=0.105$ \\
\hline M2 & $0.13 \times 0.33+0.67 \times 0.14=0.137$ & $0.35 \times 0.16+0.88 \times 0.18=0.214$ & $0.51 \times 0.2+0.8 \times 0.10=0.189$ \\
\hline M3 & $0.54 \times 0.33+0.67 \times 0.23=0.33$ & $0.07 \times 0.16+0.88 \times 0.57=0.513$ & $0.07 \times 0.2+0.8 \times 0.56=0.464$ \\
\hline M4 & $0.36 \times 0.33+0.67 \times 0.55=0.490$ & $0.37 \times 0.16+0.88 \times 0.14=0.182$ & $0.13 \times 0.2+0.8 \times 0.27=0.245$ \\
\hline
\end{tabular}

\section{Selection of feasible leaching method}

The overall priority vector for selection of leaching methods was determined from the PV values with respect to alternatives and sub-criteria (Table 6 and Table 8). PV value from Table 8 were multiplied the PV value from Table 6 in order to select the feasible leaching method with respect to alternatives and subcriteria. The final values are tabulated in Table 9. Similarly, the results obtained in Table 9 were further multiplied by PV value of criteria to get final scores of each method and tabulated in Table 10. It can be observed from Table 10 that thiosulfate $(M 1)$ scored $=0.39$, iodide $(M 2)=0.16$, aqua-regia $(M 3)=0.39$ and thiourea (M4) $=0.39$. As per Saaty (1977) the alternative with the highest priority would be the most suitable method. So, alternative with highest priority is aqua-regia (M3) and thiourea (M4) which are highest compared to other alternatives. Hence having worked out the AHP technique, the aqua-regia (M3) and thiourea (M4) method is judged to be the most suitable method for the recovery of heavy metals from e-waste.

Table 9 Overall priority vectors for alternatives with respect to criteria 


\begin{tabular}{|llll|}
\hline & EF (0.65) & RI (0.23) & RG (0.12) \\
\hline M1 & 0.069 & 0.123 & 0.105 \\
\hline M2 & 0.137 & 0.214 & 0.189 \\
\hline M3 & 0.332 & 0.513 & 0.464 \\
\hline M4 & 0.490 & 0.182 & 0.245 \\
\hline
\end{tabular}

Table 10 Final ranking of leaching method

\begin{tabular}{|lll|}
\hline & PV for EF, El and RR & Final PV \\
\hline M1 & $0.069 \times 0.65+0.23 \times 0.123+0.12 \times 0.105$ & 0.09 \\
\hline M2 & $0.137 \times 0.65+0.23 \times 0.214+0.12 \times 0.189$ & 0.16 \\
\hline M3 & $0.332 \times 0.65+0.23 \times 0.513+0.12 \times 0.464$ & 0.39 \\
\hline M4 & $0.490 \times 0.65+0.23 \times 0.182+0.12 \times 0.245$ & 0.39 \\
\hline
\end{tabular}

\section{Conclusions And Recommendation}

Hydrometallurgical methods have been effectively used for metals recovery from e-waste around the world, owing to its simplicity and controlled process with high recovery rates at relatively low costs, and a variety of studies using various hydrometallurgical methods for metals recovery from e-waste has been published every year. This study provides an up-to-date review of the hydrometallurgical recovery of metals from e-waste and gives perspectives of this particular area, which is expected to provide an insight for the selection of suitable hydrometallurgical leaching and purification methods that would be the future focuses of this area. Further, systematic approach, Analytic Hierarchy Process was used for selection of feasible (suitable) leaching method for heavy metal recovery. The overall priorities of the sub criteria with respect to the criteria for each method are given in this study.

The selection of feasible leaching method is done based on the final ranking of the alternatives using AHP technique. From the final ranking, thiosulfate $(M 1)$ scored $=0.09$, iodide $(M 2)=0.16$, aqua-regia $(M 3)$ $=0.39$ and thiourea $(M 4)=0.39$. As per Saaty the alternative with the highest weight would be the most suitable method. So, alternative with highest priority is aqua-regia (M3) and thiourea (M4) which are highest compared to other alternatives. Hence having worked out the AHP technique, the aqua-regia (M3) and thiourea (M4) method is judged to be the most suitable method for the recovery of heavy metals from e-waste. More attention should be paid on developing novel leaching methods using environmentally benign and easily recycled lixiviant and oxidant. Complex metal compositions present in e-waste, therefore, simplify the downstream purification process, careful leaching should be considered. 
Suitable methods for the purification and recovery of metals from leaching solution should be decided based on the specific leaching solution.

\section{Declarations}

\section{Ethical approval}

Not applicable

\section{Consent to Participate}

Not applicable

\section{Consent to Publish}

Not applicable

\section{Data Availability Statement}

All data used during the study appear in the published article.

\section{Competing interest}

No competing interests

\section{Funding}

The authors are thankful to Guru Gobind Singh Indraprastha University, Dwarka, New Delhi, India, financial support to carry out the research work.

\section{Authors Contributions}

Garima Minocha wrote full manuscript and calculations part, Vinita Khandegar and Sanigdha Acharya did the final editing.

\section{Acknowledgments}

The authors are thankful to Guru Gobind Singh Indraprastha University, Dwarka, New Delhi, India, for providing facilities to carry out the research work in the concerned area.

\section{References}

1. Ahuja A, Bhaskar S (2018) E-Waste On The Rise: India Is Now One Of The Top Five E-Waste Producers In The World

2. Ashiq A, Kulkarni J, Vithanage M (2019) Hydrometallurgical recovery of metals from e-waste. Elsevier Inc. 
3. Awasthi AK, Zeng X, Li J (2016) Environmental pollution of electronic waste recycling in India: A critical review. Environ. Pollut. 211:259-270

4. Birloaga I, Vegliò $F$ (2018) WEEE characterization, division, and regulation. Waste Electr Electron Equip Recycl Aqueous Recover Methods 1-12. https://doi.org/10.1016/B978-0-08-102057-9.00001-9

5. Chatterjee S (2011) Electronic Waste and India. 1-15

6. Chauhan G, Jadhao PR, Pant KK, Nigam KDP (2018) Novel technologies and conventional processes for recovery of metals from waste electrical and electronic equipment: Challenges \& opportunities A review. J Environ Chem Eng 6:1288-1304. https://doi.org/10.1016/j.jece.2018.01.032

7. Cui J, Roven HJ (2011) Electronic Waste. Elsevier Inc.

8. Dissanayake V (2014) Electronic Waste

9. European P (2014) Document 32014L0095 Title and reference. 1-4

10. Frazzoli C, Orisakwe OE, Dragone R, Mantovani A (2010) Diagnostic health risk assessment of electronic waste on the general population in developing countries' scenarios. Environ Impact Assess Rev 30:388-399. https://doi.org/10.1016/j.eiar.2009.12.004

11. Havlík T (2008) Experimental Methods of Investigating Hydrometallurgical Processes. Hydrometallurgy 309-340. https://doi.org/10.1533/9781845694616.309

12. Kaya M (2016) Recovery of metals and nonmetals from electronic waste by physical and chemical recycling processes. Waste Manag 57:64-90. https://doi.org/10.1016/j.wasman.2016.08.004

13. Khaliq A, Rhamdhani MA, Brooks G, Masood S (2014) Metal extraction processes for electronic waste and existing industrial routes: A review and Australian perspective. Resources 3:152-179. https://doi.org/10.3390/resources3010152

14. Li H, Eksteen J, Oraby E (2018) Hydrometallurgical recovery of metals from waste printed circuit boards (WPCBs): Current status and perspectives - A review. Resour Conserv Recycl 139:122-139. https://doi.org/10.1016/j.resconrec.2018.08.007

15. Mohan V (2020) India third largest e-waste generator in the world, capacity limited to treat only one fourth of its waste. Times of India

16. Pandey P, Govind M (2020) Socio-technological challenges in formalization of E-waste recycling in India. INC

17. Puckett J, Byster L, Westervelt S, et al (2002) Exporting Harm. 1-51

18. Saaty TL (1977) A scaling method for priorities in hierarchical structures. J Math Psychol 15:234281. https://doi.org/10.1016/0022-2496(77)90033-5

19. Tunsu C, Retegan T (2016) Hydrometallurgical Processes for the Recovery of Metals from WEEE. WEEE Recycl Res Dev Policies 139-175. https://doi.org/10.1016/B978-0-12-803363-0.00006-7

20. Turaga RMR, Bhaskar K, Sinha S, et al (2019) E-Waste Management in India: Issues and Strategies. Vikalpa J Decis Makers 44:127-162. https://doi.org/10.1177/0256090919880655

21. Vidyadhar A (2016) A Review of Technology of Metal Recovery from Electronic Waste. E-Waste Transit - From Pollut to Resour. https://doi.org/10.5772/61569 
22. Yu L (2017) Research on evaluation index of green campus based on AHP method. Proc - 2016 Int Conf Intell Transp Big Data Smart City, ICITBS 2016 249-252. https://doi.org/10.1109/ICITBS.2016.25

\section{Figures}

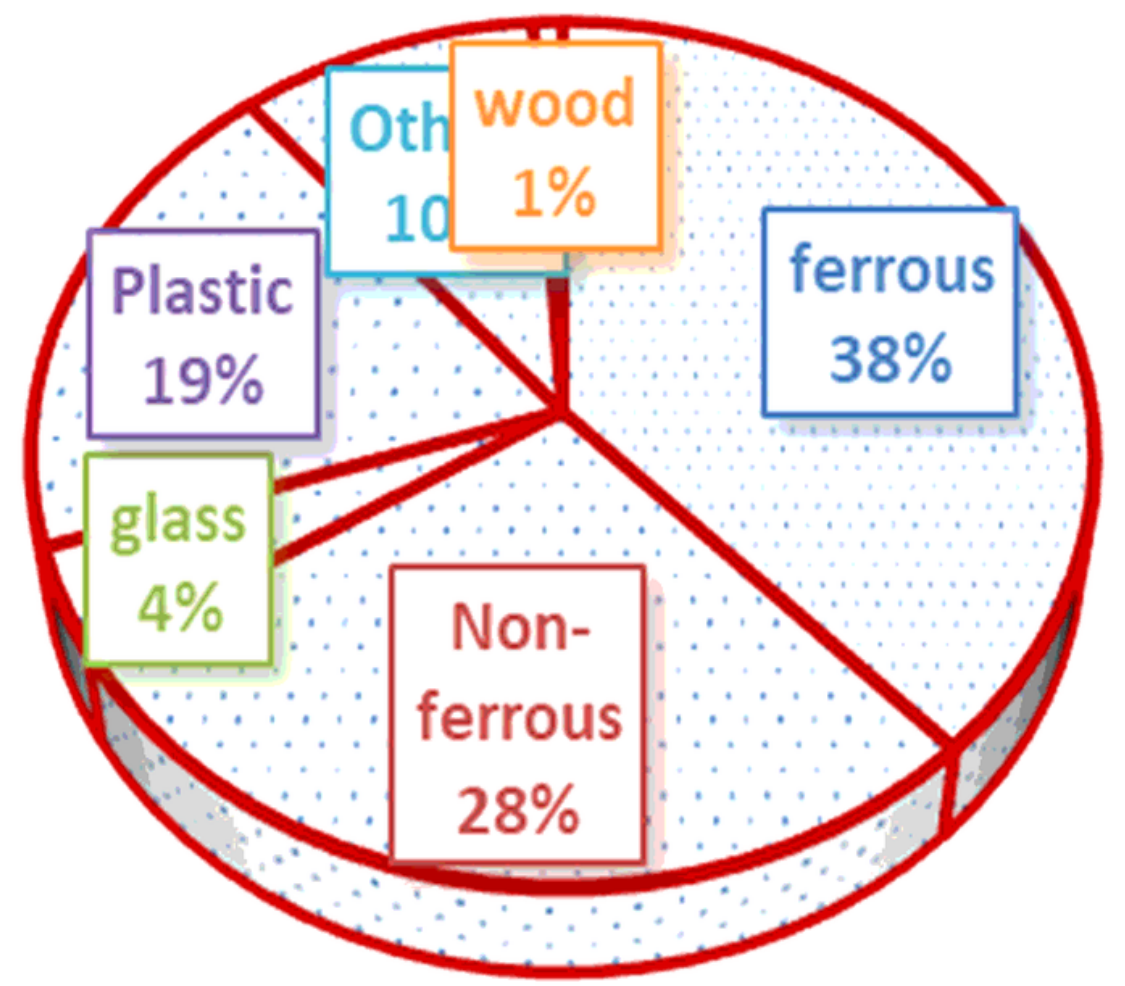

Figure 1

Composition of electronic and electrical products 


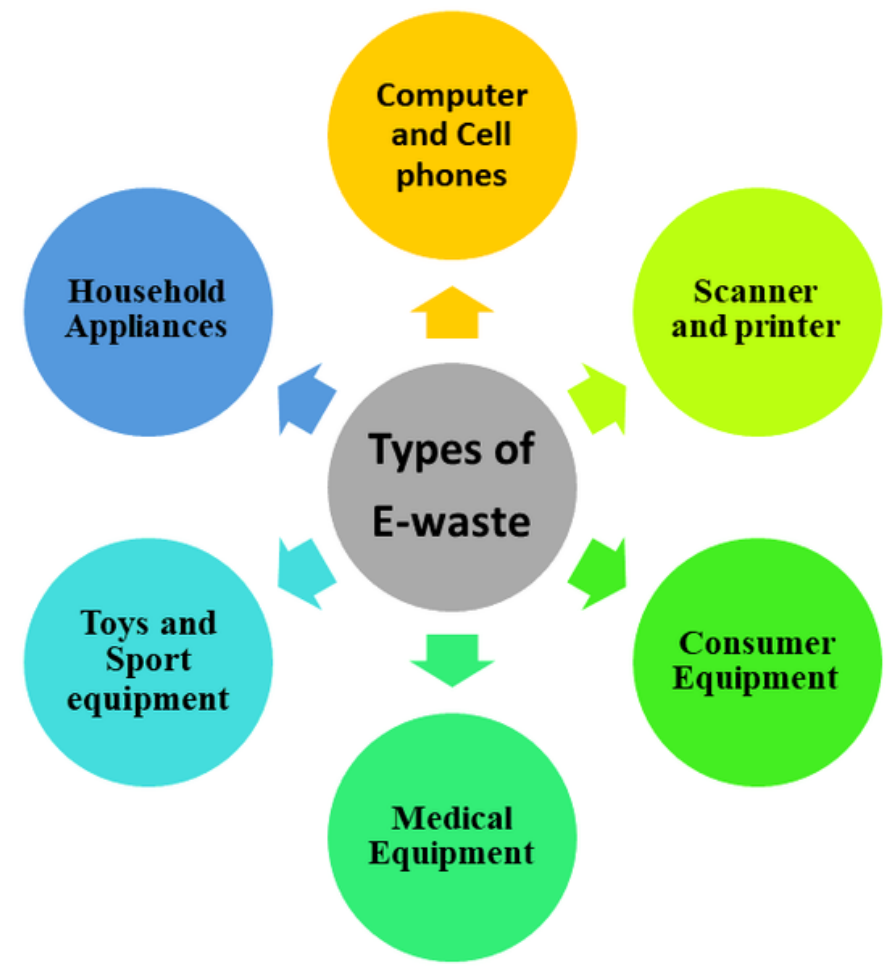

Figure 2

Different categories of E-waste

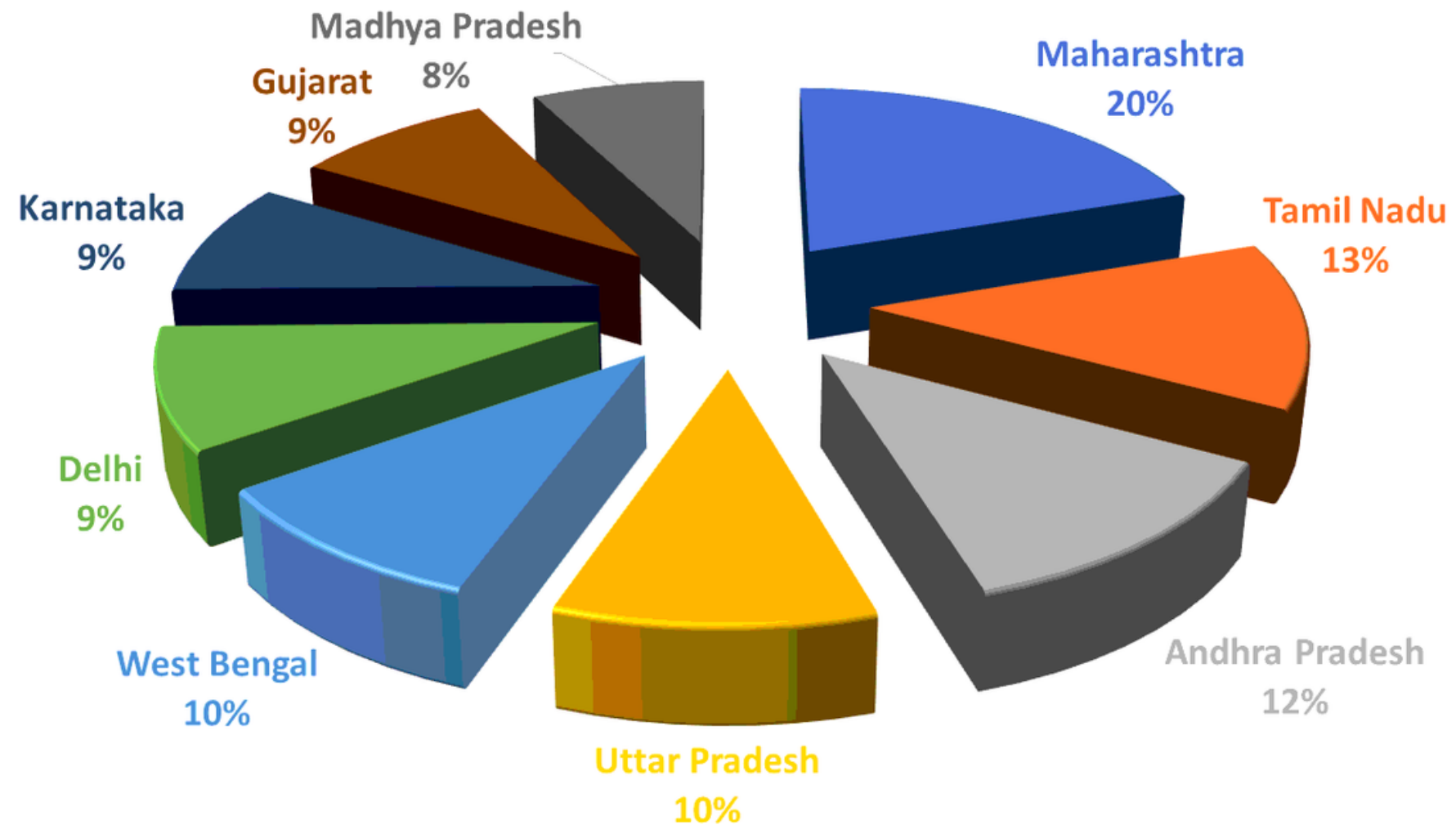


Figure 3

State wise E-waste generation in India

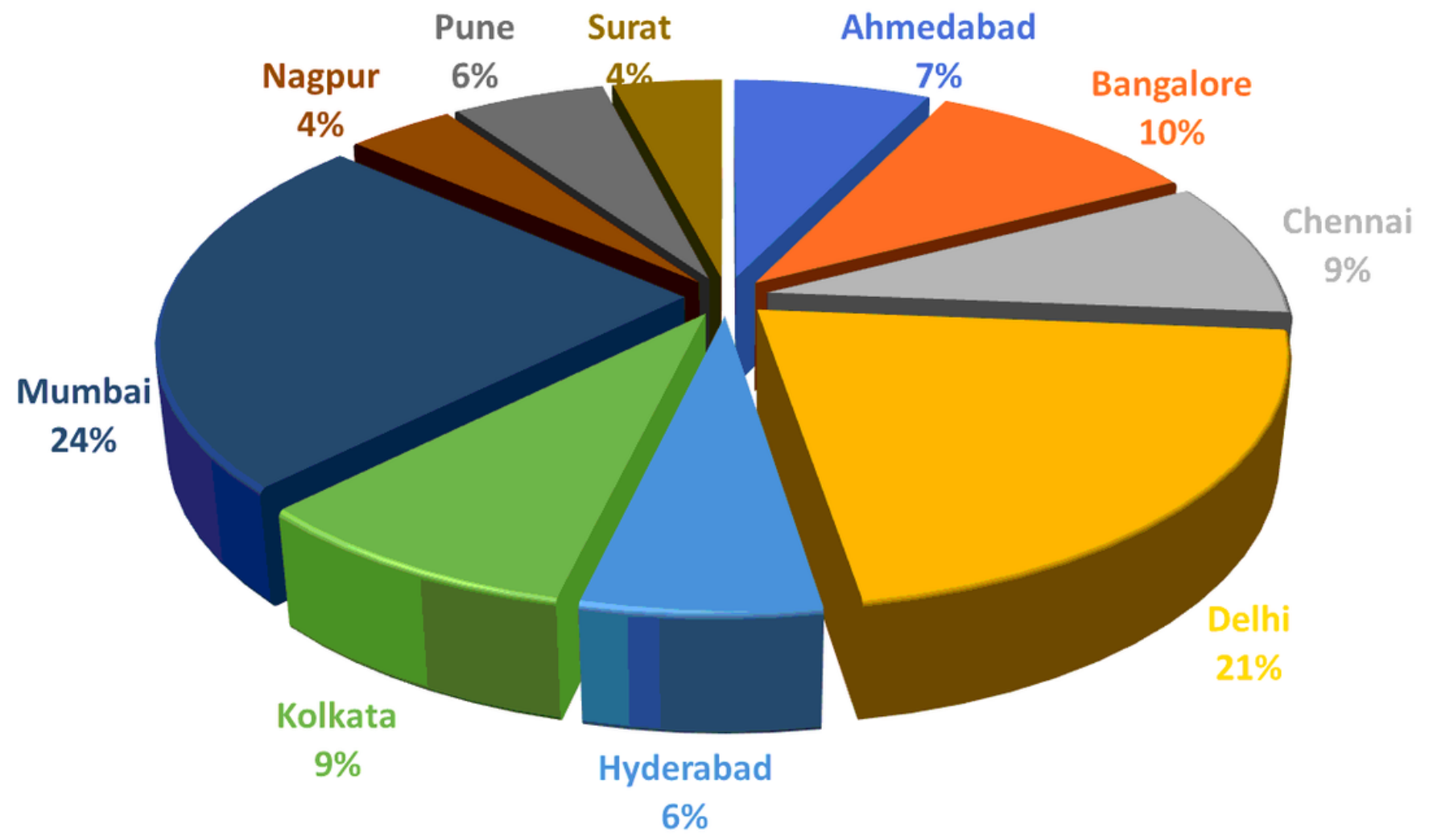

Figure 4

City wise E-waste generation in India 


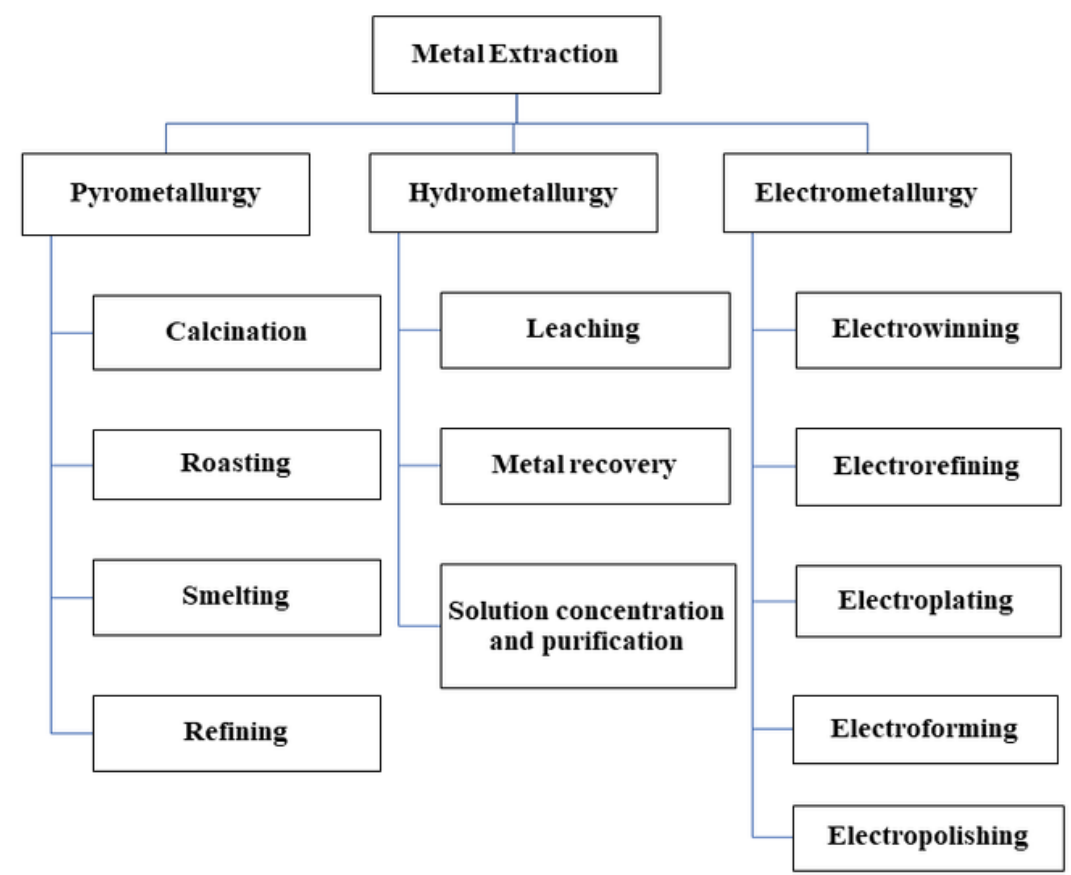

Figure 5

Metal extraction process from E-waste
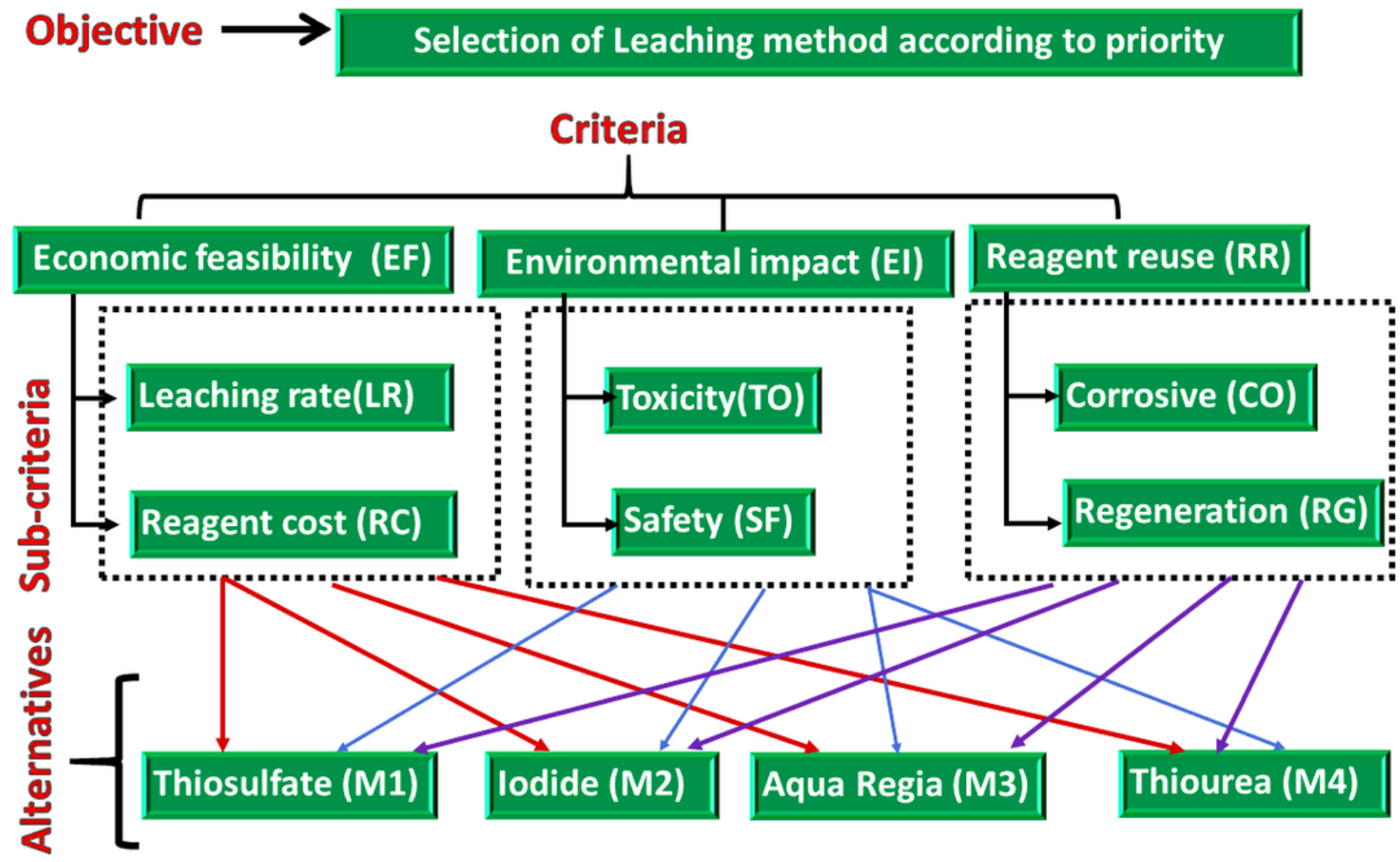
Figure 6

Three-level hierarchy model for selection of feasible leaching method 